\title{
Modular Polyoxometalate-Layered Double Hydroxide Composites as Efficient Oxidative Catalysts
}

\begin{abstract}
Yang Chen, ${ }^{\text {a† }}$ Zhixiao Yao, ${ }^{\text {a† }}$ Haralampos N. Miras ${ }^{\mathrm{b} *}$ and Yu-Fei Song ${ }^{\mathrm{a} *}$
Abstract: The exploitation of intercalation techniques in the field of two-dimensional layered materials offers unique opportunities for controlling chemical reactions in confined spaces and developing nanocomposites with desired functionality. In this paper, we demonstrate the exploitation of the novel and facile 'one-pot' anionexchange method for the functionalization of layered double hydroxides (LDHs). As a proof of concept, we demonstrate the intercalation of a series of polyoxometalate (POM) clusters, $\mathrm{Na}_{3}\left[\mathrm{PW}_{12} \mathrm{O}_{40}\right] \cdot 15 \mathrm{H}_{2} \mathrm{O} \quad\left(\mathrm{Na}_{3} \mathrm{PW}_{12}\right), \quad \mathrm{K}_{6}\left[\mathrm{P}_{2} \mathrm{~W}_{18} \mathrm{O}_{62}\right] \cdot 14 \mathrm{H}_{2} \mathrm{O} \quad\left(\mathrm{K}_{6} \mathrm{P}_{2} \mathrm{~W}_{18}\right)$, and $\mathrm{Na}_{9} \mathrm{LaW}_{10} \mathrm{O}_{36} \cdot 32 \mathrm{H}_{2} \mathrm{O}\left(\mathrm{Na}_{9} \mathrm{LaW}_{10}\right)$ into tris(hydroxymethyl)aminomethane (Tris) modified layered double hydroxides (LDHs) under ambient conditions without the necessity of degassing $\mathrm{CO}_{2}$. Investigation of the resultant intercalated materials of Tris-LDHs$\mathrm{PW}_{12}$ (1), Tris-LDH- $\mathrm{P}_{2} \mathrm{~W}_{18}$ (2), and Tris-LDH-LaW 10 (3) for the degradation of methylene blue $(M B)$, rhodamine $B(R B)$ and crystal violet $(C V)$ has been carried out, where Tris-LDH-PW 12 reveals the best performance in the presence of $\mathrm{H}_{2} \mathrm{O}_{2}$. Additionally, degradation of a mixture of RB, MB and CV by Tris-LDH-PW 12 follows the order of $C V>M B>R B$, which is directly related to the designed

wastewater treatment using photocatalysis techniques exhibit a number of disadvantages, such as harsh reaction conditions, high operation cost and the decreased photocatalytic efficiency due to poor light transmittance of high concentration dye solutions. Under such circumstances, the chemical oxidation technologies have been considered as promising alternative methodologies due to their ability to degrade efficiently toxic and biologically refractory organic contaminants in aqueous solutions. ${ }^{[7]}$ The use of advanced oxidation processes (AOPs) with the generation of highly reactive radicals have attracted enormous attention in the dye polluted wastewater treatment since they demonstrated desirable functionality at or near ambient temperatures and pressures. ${ }^{[8-9]}$ However, most of the catalysts used in catalytic oxidation processes are metal-based homogeneous oxides ${ }^{[10-11]}$, and the catalysts separation is technically challenging and economically unfavorable. Moreover, many active homogeneous catalysts including transitional metal complexes are toxic. Thus, it is highly desirable to develop new and efficient heterogeneous catalytic systems.
\end{abstract} accessible area of the interlayer space. Also, the composite can be readily recycled and reused at least ten cycles without measurable decrease of activity.

\section{Introduction}

Nowadays, dye contamination of water sources has become a major source of environmental pollution due to the uncontrolled development of dye industry, which has attracted considerable attention for several decades due to the toxicity, and high chemical oxygen demand (COD) content. ${ }^{[1]}$ The removal of dyes from polluted water sources using conventional technologies is problematic due to wide range of parameters that needs to be taken into consideration in every case such as dye's concentration, $\mathrm{pH}$ range of the reaction medium, temperature etc. ${ }^{[2-4]}$ In recent years, the photocatalytic degradation of organic pollutants by photocatalysts has drawn considerable attention due to their low toxicity and the production of $\mathrm{CO}_{2}$ and $\mathrm{H}_{2} \mathrm{O}$ as main decomposition products. ${ }^{[5-6]}$ However, in practice

[a] Y Chen, Z Yao, and Prof. Y. F. Song*

State Key Laboratory of Chemical Resource Engineering,

B eijing University of Chemical Technology,

Beijing, 100029, P. R. China.

Tel/Fax: +86-10-64431832;

Email: songyufei@ hotmail.com or songyf@ mail.buct.edu.cn

$\dagger$ These authors contributed equally.

[b] Dr. H. N. Miras*

WestCHEM, School of Chemistry, University of Glasgow

Glasgow, G12 8QQ, UK.

Email: charalampos.moiras@glasgow.ac.uk

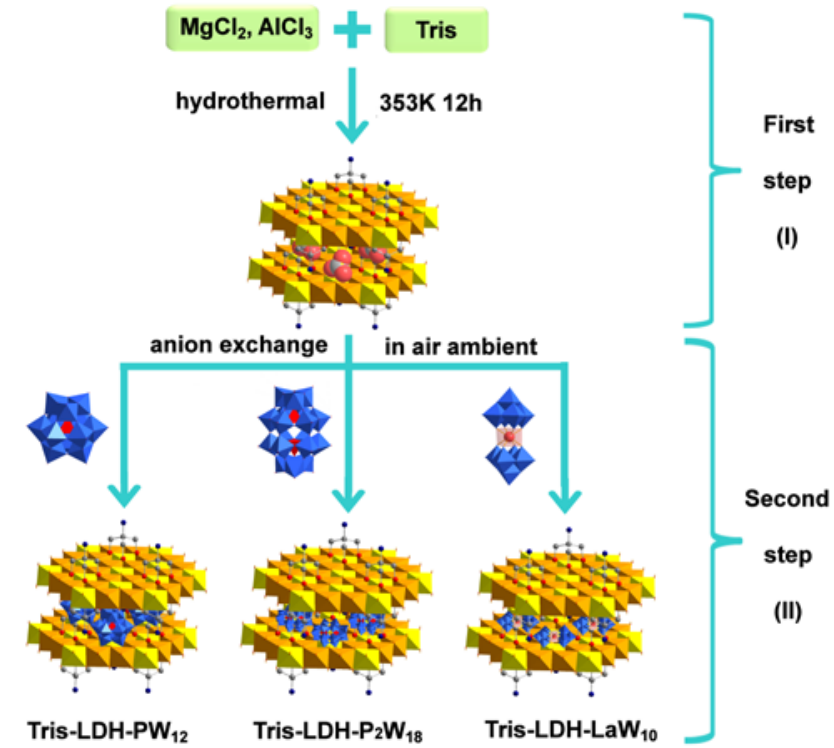

Scheme 1. Schematic representation of the synthesis of I) Tris-modified LDHS and II) a series of classical POMs intercalated into Tris-modified LDHs.

Layered double hydroxides (LDHs) are a large class of layered anionic clays with 2D-organzied layered structure and general formula of $\left[\mathrm{M}^{2+}{ }_{1-\mathrm{x}} \mathrm{M}^{3+}{ }_{\mathrm{x}}(\mathrm{OH})_{2}\right]^{\mathrm{x+}}\left(\mathrm{A}^{\mathrm{n}-}\right)_{\mathrm{x} / \mathrm{n}} \cdot \mathrm{mH}_{2} \mathrm{O}$, in which $\mathrm{M}^{2+}$ and $\mathrm{M}^{3+}$ are di- and trivalent metal cations of host layer; $\mathrm{A}^{\mathrm{n}-}$ is $\mathrm{n-}$ valent interlayer exchangeable guest anions. ${ }^{[12-15]}$ 


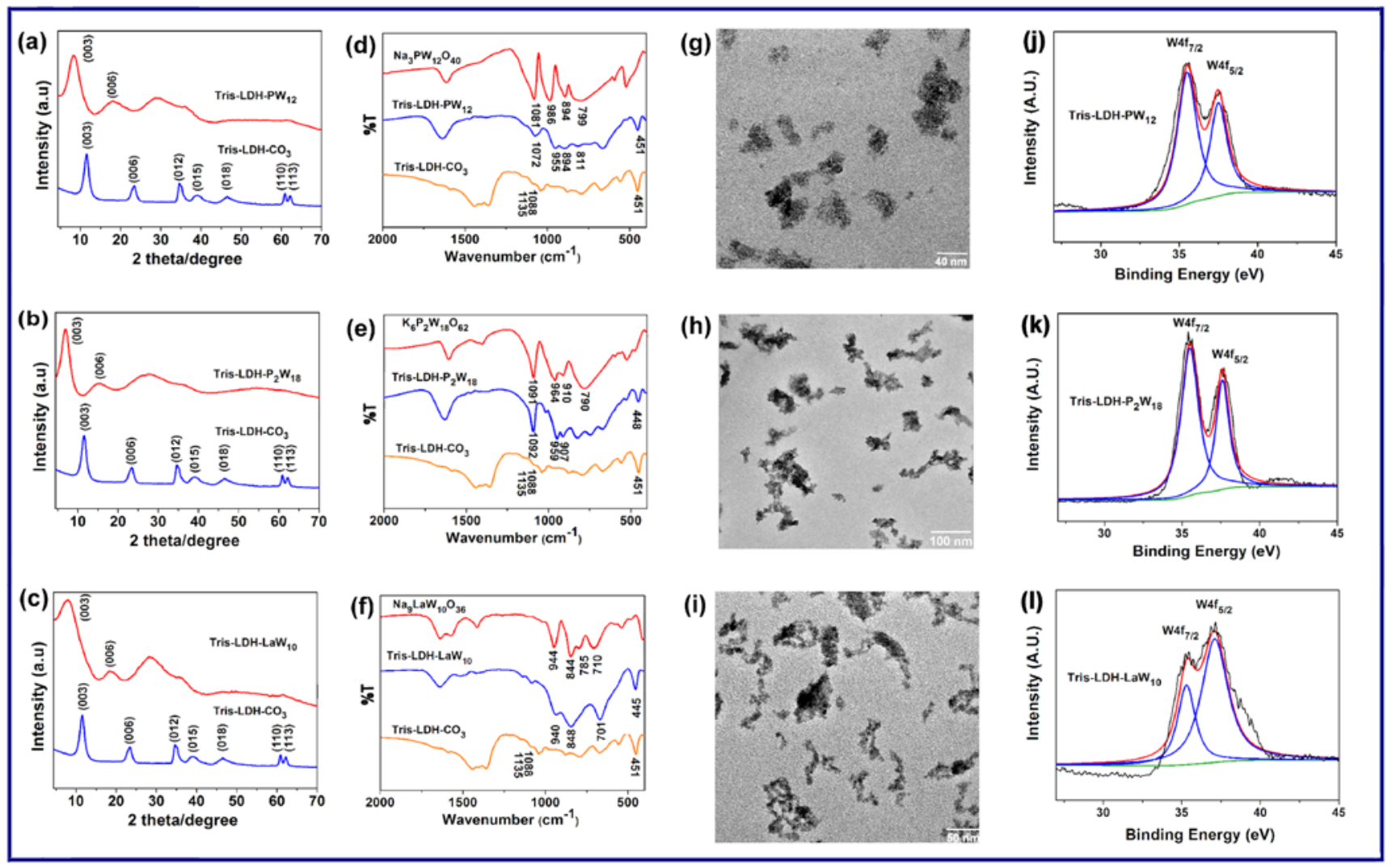

Figure 1. (a-c) XRD patterns; (d-f) FT-IR spectra; (g-i) TEM images and (j-I) XPS spectra for the $\mathrm{W}_{4 \mathrm{f}}$ core level spectra of the as-prepared Tris-LDH-PW 12 , TrisLDH- $\mathrm{P}_{2} \mathrm{~W}_{18}$ and Tris-LDH-LaW 10 .

Owing to the specific structure and versatility in chemical composition, LDHs have been widely used as multi-functional materials in the fields of photocatalytic water splitting and degradation of environmental pollutants etc. ${ }^{[16,17]}$ Previous work have demonstrated that the intercalation of polyoxometalates (POMs) into LDHs inter-lamellar gallery can effectively depress the aggregation, enhance the dispersion and stability of the guests. ${ }^{[18-22]}$ Most importantly, compared with other immobilized systems such as $\mathrm{SiO}_{2} / \mathrm{POMs}, \mathrm{ZrO}_{2} / \mathrm{POMs}, \mathrm{Al}_{2} \mathrm{O}_{3} / \mathrm{POMs}$ etc, the LDHs/POMs nanocomposites would exhibit the following advantages: (1) the host-guest interactions (e.g., electrostatic, van der Waals, or hydrogen bonding) induce a homogeneous distribution of POMs guests at the molecular level; (2) the chemical stability and photo-stability of POMs can be largelyimproved by the introduction of inorganic LDH component; (3) the POM-leaching issue for many heterogeneous catalysts is not pronounced after intercalation. ${ }^{[19,22]}$ As a result, the nanocomposite materials of LDHs/POMs are a class of versatile and attractive materials and have shown great advantages over LDHs or POMs alone.

Nevertheless, the use of traditional synthetic methods such as co-precipitation, direct exchange or reconstitution for preparation of $\mathrm{POMS} / \mathrm{LDHs}$ nanocomposites is challenging because: ${ }^{[18]}$ (i) impurities can be observed in most cases in the XRD patterns of LDHs/POMs composites; (ii) such intercalation is closely related to the geometry, charge and size of POMs. For example, the $\left[\mathrm{PW}_{12} \mathrm{O}_{40}\right]^{3-}$ is very unlikely to be intercalated into LDHs with traditional synthetic methods because the negative charge of the cluster is below 4; (iii) it is hard to carry out exchange reaction when $\mathrm{CO}_{3}{ }^{2-}$ is the intercalated anions due to the strong affinity of $\mathrm{LDHs}$ for $\mathrm{CO}_{3}^{2-}$ anions.

Under such circumstances, the development of new methods for the preparation of such LDHs/POMs nanocomposites is highly desirable. Additionally, the intercalated LDHs/POMs composite materials might affect the catalytic performance, stability and recyclability due to the potnetial synergistic effect arising from the POM's catalytic activity within the LDH's confined space. In this work, we reported the general applicability of a novel, facile, one-pot synthetic approach for the intercalation of three classical POMs including Keggin, Dawson and Weakley type clusters into tris(hydroxymethyl)aminomethane (Tris) modified LDHs under ambient conditions without the necessity of degassing $\mathrm{CO}_{2}$ (Scheme 1). Further application of these Tris-LDH-POMs for degradation of dyes including methylene blue $(M B)$, rhodamine $B(R B)$ and crystal violet $(C V)$ has been carried out.

\section{Results and Discussion}

Tris-modified layered double hydroxides (LDHs) have been prepared successfully by mixing $\mathrm{MgCl}_{2} \cdot 6 \mathrm{H}_{2} \mathrm{O}, \mathrm{AlCl}_{3} \cdot 6 \mathrm{H}_{2} \mathrm{O}$ and Tris in aqueous solution, leading to the formation of Tris-LDH$\mathrm{CO}_{3 .}{ }^{[23]}$ Ion exchange of the classical Na-PW 12 with Tris-LDH$\mathrm{CO}_{3}$ under ambient conditions without necessity of $\mathrm{CO}_{2}$ degassing results in the formation of new intercalated assembly 
of Tris-LDH-PW ${ }_{12}$. Employing traditional synthetic methods for the preparation of POMs/LDHs can not be carried out in air because $\mathrm{CO}_{2}$ can easily occupy the interlayer space of LDHs. Thus, the intercalation of POMs into the inter-lamellar region of $\mathrm{LDHs}-\mathrm{CO}_{3}$ does not work well using direct exchange reaction with $\mathrm{LDHs}-\mathrm{CO}_{3}$ as the presursor. In contrast, the modification of the LDHs layers with Tris alters considerably the dimensions of the Tris-LDHs' ab plane making possible the exchange the $\mathrm{CO}_{3}{ }^{2-}$ ions in the presence of POMs. ${ }^{[19 b]}$

The as-prepared nanocomposite materials of Tris-LDH-POMs have been characterized by powder X-ray diffraction (XRD), fourier transform infrared spectroscopy (FT-IR), and high resolution transmission electron microscopy (HRTEM) and XPS (Figure 1). The XRD patterns of the Tris-LDH- $\mathrm{CO}_{3}$ show the characteristic peaks (003), (006), (110) and (113) at 2, $=11.5^{\circ}$, $23.4^{\circ}, 60.9^{\circ}$ and $62.2^{\circ}$, respectively. After the ion exchange of $\mathrm{CO}_{3}{ }^{2-}$ with $\left[\mathrm{PW}_{12} \mathrm{O}_{40}\right]^{3-},\left[\mathrm{P}_{2} \mathrm{~W}_{18} \mathrm{O}_{62}\right]^{6-}$ and $\left[\mathrm{LaW}_{10} \mathrm{O}_{36}\right]^{9-}$, the XRD patterns of Tris-LDH-PW 12 , Tris-LDH-PW 18 and Tris-LDH-LaW 10 exhibit the (003) and (006) at $2,=8.4^{\circ}$ and $17.1^{\circ}, 7.4^{\circ}$ and $15.2^{\circ}$ $8.4^{\circ}$ and $17.0^{\circ}$ respectively, corresponding to $d$ values of 1.05 and $0.52 \mathrm{~nm}, 1.19$ and $0.58 \mathrm{~nm}, 1.05$ and $0.52 \mathrm{~nm}$, respectively. Compared with the XRD pattern of the pristine Tris- $\mathrm{LDH}-\mathrm{CO}_{3}$, the basal (003) and (006) reflections of Tris-LDH-POMs shift to lower 2 , indicating the successful intercalation of the series of POMs into the Tris-modified LDHs. As such, Tris-modified LDH show a much improved intercalation ability compared to the unmodified LDHs. Most importantly, no impurity phase close to (003) has been observed.

FT-IR spectra of Tris-LDH-POMs display the characteristic absorption peaks at 894 and $811 \mathrm{~cm}^{-1}$ for Tris-LDH-PW 12,907 $\mathrm{cm}^{-1}$ for Tris-LDH- $\mathrm{P}_{2} \mathrm{~W}_{18}, 848 \mathrm{~cm}^{-1}$ and $701 \mathrm{~cm}^{-1}$ for Tris-LDH$\mathrm{LaW}_{10}$, which can be assigned to the vibration of $\mathrm{W}-\mathrm{O}-\mathrm{W}$ bonds. ${ }^{[24]}$ And the characteristic asymmetric vibration of $\mathrm{W}-\mathrm{O}$ bond shifts significantly from $986 \mathrm{~cm}^{-1}$ in $\mathrm{Na}_{3} \mathrm{PW}_{12} \mathrm{O}_{40}$ to 955 $\mathrm{cm}^{-1}$ in Tris-LDH-PW 12 , from $964 \mathrm{~cm}^{-1}$ in $\mathrm{K}_{2} \mathrm{P}_{2} \mathrm{~W}_{18} \mathrm{O}_{62}$ to $959 \mathrm{~cm}^{-1}$ for Tris-LDH- $\mathrm{P}_{2} \mathrm{~W}_{18}$, and $940 \mathrm{~cm}^{-1}$ for Tris-LDH-LaW ${ }_{10}$, respectively, suggesting the presence of strong electrostatic interactions and hydrogen bondings between the host layers and the guest anions. The asymmetric vibration peak can be observed at $1072 \mathrm{~cm}^{-1}$ for Tris-LDH-PW 12 , and $1092 \mathrm{~cm}^{-1}$ for Tris-LDH- $\mathrm{P}_{2} \mathrm{~W}_{18}$ due to the $\mathrm{P}-\mathrm{O}^{[25]}$ vibration.

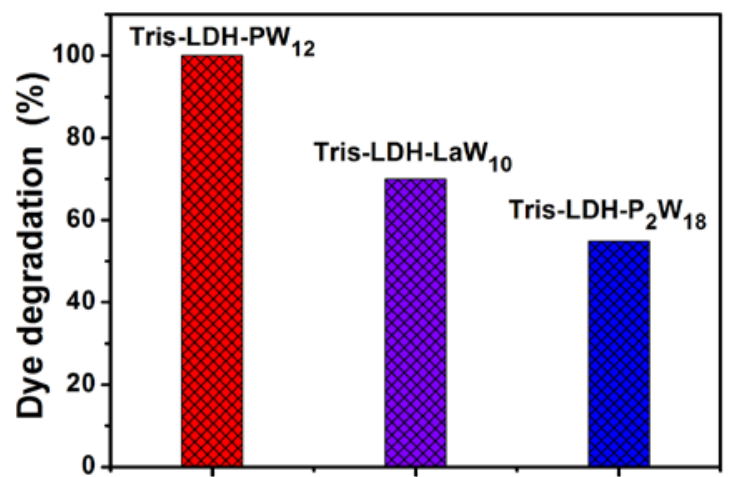

Figure 2. Comparison of degradation efficiency with different Tris-LDH-POMs under the same experiment condition. The catalyst (Tris-LDH-PW $\mathrm{L}_{12}$, or TrisLDH- $\mathrm{P}_{2} \mathrm{~W}_{18}$ or Tris-LDH-LaW 10$) 50 \mathrm{mg} ; \mathrm{H}_{2} \mathrm{O}_{2}=500 \mu \mathrm{l} ; \mathrm{MB}=10 \mathrm{mg} / \mathrm{L} ; \mathrm{T}=30$ ${ }^{\circ} \mathrm{C}, \mathrm{t}=140 \mathrm{~min}$.

HRTEM images of Tris-LDH-PW ${ }_{12}$, Tris-LDH-PW 18 and Tris$\mathrm{LDH}-\mathrm{LaW}_{10}$ (Figure $1 \mathrm{~g}, 1 \mathrm{~h}$ and $\mathrm{li}$ ) indicate that the nanoparticles exhibits irregular morphology with uniform dispersion of $\left[\mathrm{PW}_{12} \mathrm{O}_{40}\right]^{3-},\left[\mathrm{P}_{2} \mathrm{~W}_{18} \mathrm{O}_{62}\right]^{6-}$ and $\left[\mathrm{LaW}_{10} \mathrm{O}_{36}\right]^{9-}$ as small black dots. In contrast, TEM images (Figure S1) of the precursor Tris-LDH$\mathrm{CO}_{3}$ show the uniform nanoparticles with a rectangular shape and average size $\sim 20 \mathrm{~nm}$. The irregular morphology may be caused by agglomeration during the anion-exchange process. Figure $1(j-I)$ show the XPS core level spectra of $W_{4 f}$ of Tris-LDH$\mathrm{PW}_{12}$, Tris-LDH- $\mathrm{P}_{2} \mathrm{~W}_{18}$ or Tris-LDH-LaW ${ }_{10}$, which have been deconvoluted into doublets. It can be seen that the doublets consist of $W_{4 f_{7 / 2}}$ and $W 4 f_{5 / 2}$ at $35.5 \mathrm{eV}$ and $37.5 \mathrm{eV}$ for Tris-LDH$\mathrm{PW}_{12}, 35.5 \mathrm{eV}$ and $37.6 \mathrm{eV}$ for Tris-LDH- $\mathrm{P}_{2} \mathrm{~W}_{18}, 35.3 \mathrm{eV}$ and $37.1 \mathrm{eV}$ for Tris-LDH-LaW ${ }_{10}$, respectively, which can be assigned to the $\mathrm{W}-\mathrm{O}$ configuration and typically observed for the $\mathrm{W}^{6+[26]}$.

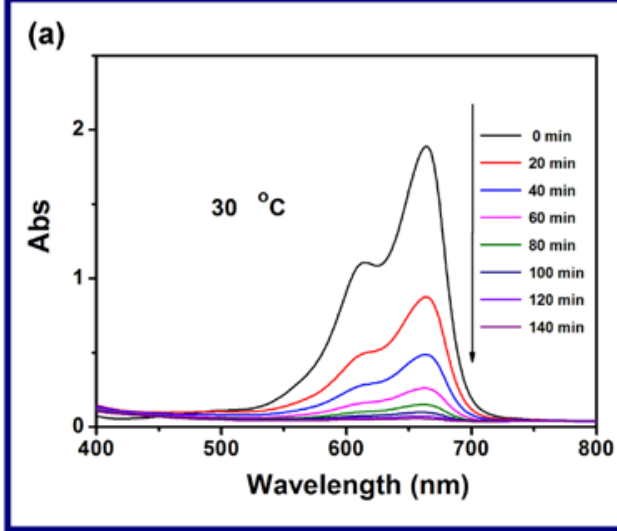

(b)
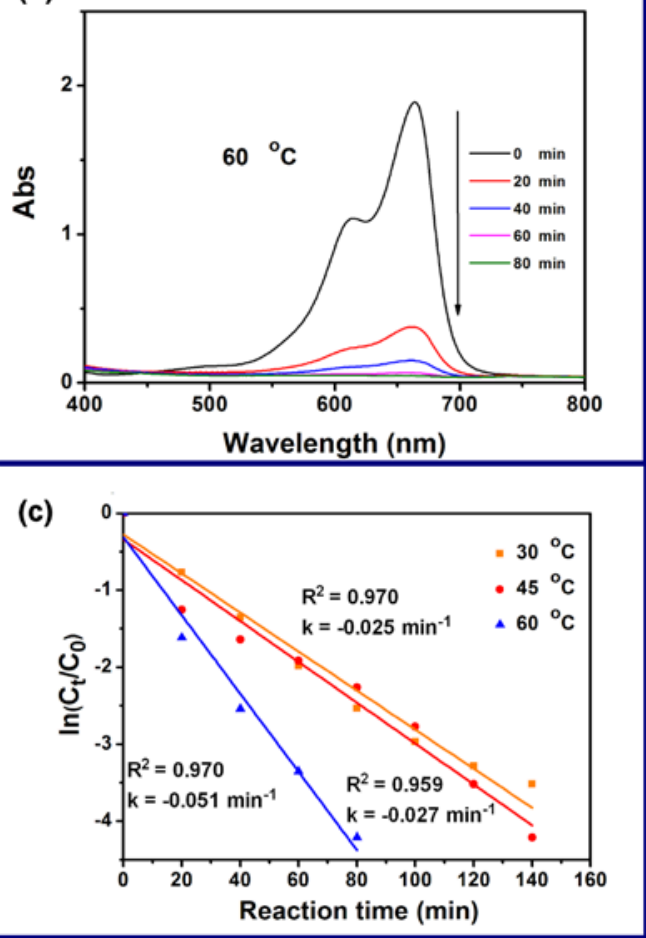

Figure 3. Effect of temperature on $M B$ degradation. (a) $\mathrm{T}=30{ }^{\circ} \mathrm{C}$; (b) $\mathrm{T}=60$ ${ }^{\circ} \mathrm{C}$ (c) reaction kinetic plots for the degradation of $\mathrm{MB}$ versus time. Experiment condition: Tris-LDH-PW $1250 \mathrm{mg} ; \mathrm{MB}=10 \mathrm{mg} / \mathrm{L}(50 \mathrm{ml}) ; \mathrm{H}_{2} \mathrm{O}_{2}=500 \mu \mathrm{l}$.

The ${ }^{31} \mathrm{P}$ NMR spectra exhibit signals centered at ' $=-4 \mathrm{ppm}$ for Tris-LDH-PW 12 and ' = -6.5 ppm for Tris-LDH- $\mathrm{P}_{2} \mathrm{~W}_{18}$, respectively (Figure $\mathrm{S} 4$ ), suggesting the $\mathrm{POM}$ anions have been 
intercalated into the Tris-modified LDH. ${ }^{[27]}$ Due to the successful exchange of the classical POMs of $\left[\mathrm{PW}_{12} \mathrm{O}_{40}\right]^{3-},\left[\mathrm{P}_{2} \mathrm{~W}_{18} \mathrm{O}_{62}\right]^{6-}$ and $\left[\mathrm{LaW}_{10} \mathrm{O}_{36}\right]^{9-}$ with $\mathrm{CO}_{3}{ }^{2-}$, no signal of the interlayered $\mathrm{CO}_{3}{ }^{2-}$ species at $\sim 170 \mathrm{ppm}^{[28]}$ can be observed in ${ }^{13} \mathrm{C}$ CP/MAS NMR spectrum of Tris-LDH-POMs (Figure S4). All the obtained spectroscopic data discussed above indicate the successful intercalation of the $\mathrm{PW}_{12}, \mathrm{P}_{2} \mathrm{~W}_{18}$ and $\mathrm{LaW}_{10}$. Based on the above data, the composite's suggested structure is represented in Scheme 1.

Since methylene Blue (MB) is one of the most commonly used dyes in textile industry, degradation of MB by Tris-LDH-POMs in the presence of $\mathrm{H}_{2} \mathrm{O}_{2}$ has been investigated to test the catalytic activity (Figure 2). It can be seen that Tris-LDH-PW 12 shows $>$ $99 \% \mathrm{MB}$ degradation efficiency at $\mathrm{T}=30^{\circ} \mathrm{C}$ after $140 \mathrm{~min}$ in the presence of $500 \mu \mathrm{L}$ of $\mathrm{H}_{2} \mathrm{O}_{2}$. The degradation performance of Tris-LDH-PW 12 found to be much better than the one observed for Tris-LDH- $\mathrm{P}_{2} \mathrm{~W}_{18}$ and Tris-LDH-LaW 10 , (see Figure 2).

In order to gain insight into the difference observed in composites' behaviour and make an effort to correlate their functionality with their structural features, we opted to measure the surface areas and porosities of the synthesized materials. The $\mathrm{N}_{2}$ adsorption-desorption isotherms of $\mathrm{LDH} / \mathrm{PW}_{12}$ (1), $\mathrm{LDH} / \mathrm{P}_{2} \mathrm{~W}_{18}$ (2) and $\mathrm{LDH} / \mathrm{LaW}_{10}$ (3) gave a BET surface area $15.9,7.7$ and $13.9 \mathrm{~m}^{2} / \mathrm{g}$, respectively (Table S2). Moreover, the pore volume and the average pore diameter are $0.018 \mathrm{~cm}^{3} / \mathrm{g}$ and $3.8 \mathrm{~nm}$ for $1,0.009 \mathrm{~cm}^{3} / \mathrm{g}$ and $3.8 \mathrm{~nm}$ for 2 and $0.026 \mathrm{~cm}^{3} / \mathrm{g}$ and $3.7 \mathrm{~nm}$ for $\mathbf{3}$, respectively, which are in line with the calculated results based on the Barret-J oyner-Halenda $(B \mathrm{~J} H)$ analysis. The pristine $\mathrm{LDH}$ (Tris- $\mathrm{LDH}-\mathrm{CO}_{3}$ ) and the synthesized composites display $\mathrm{H} 4$ type hysteresis loops (Figure $\mathrm{S} 2$ ), indicating that the pores are formed by the aggregation of slitshaped pores with some microporosity. ${ }^{[29]}$

\section{Effect of the temperature}

The MB degradation by Tris-LDH-PW 12 has been performed at temperatures of 30,45 and $60{ }^{\circ} \mathrm{C}$, respectively. As shown in Figure 3 , the oxidation reaction accelerates as a function of the temperature as expected due to the exponential dependency of the kinetic constants with the temperature (Arrhenius law). ${ }^{[30]}$ The increase of temperature promotes the generation of radicals and the subsequent attack to the dye molecules. ${ }^{[31]}$ It can be found that complete dye degradation can be obtained at 30,45 and $60{ }^{\circ} \mathrm{C}$ after $140 \mathrm{~min}$. Despite the fact that the $\mathrm{MB}$ degradation at $30{ }^{\circ} \mathrm{C}$ is not as fast as those observed at higher temperatures, the performances of $\mathrm{MB}$ removal at $30{ }^{\circ} \mathrm{C}$ is chosen to carry out the following studies based on the fact that use of lower temperature reduces considerably associated larger scale operational cost and eliminate the possibility of catalyst leaching after prolonged operation times. ${ }^{[32-35]}$

\section{Effects of catalyst dosage}

The influence of catalyst amount on the MB degradation has been studied by varying the catalyst dosage from 25 to $100 \mathrm{mg}$ while maintaining the oxidant/dye molar ratio constant $\left(\mathrm{H}_{2} \mathrm{O}_{2}=\right.$ $500 \mu \mathrm{l} ; \mathrm{MB}=10 \mathrm{mg} / \mathrm{L}(50 \mathrm{ml}))$. Figure 4 illustrates the $\mathrm{MB}$ removal as a function of time at different catalyst dosage in solution along with the relationship between the rate constants and catalyst dosage. With the increase of the catalyst dosage, the rate of MB degradation speeds up due to the increasing the accessible catalytically active surface area, resulting in faster generation of reactive radical species. For example, at $100 \mathrm{mg}$ Tris-LDH-PW $12,83 \%$ MB degradation can be achieved within 20 min with a degradation rate constant of $\mathrm{k}=0.039 \mathrm{~min}^{-1}$, whereas the $25 \mathrm{mg}$ of Tris-LDH-PW 12 leads to only $40 \%$ dye removal in 20 min with the degradation rate constant $\mathrm{k}=0.019 \mathrm{~min}^{-1}$.

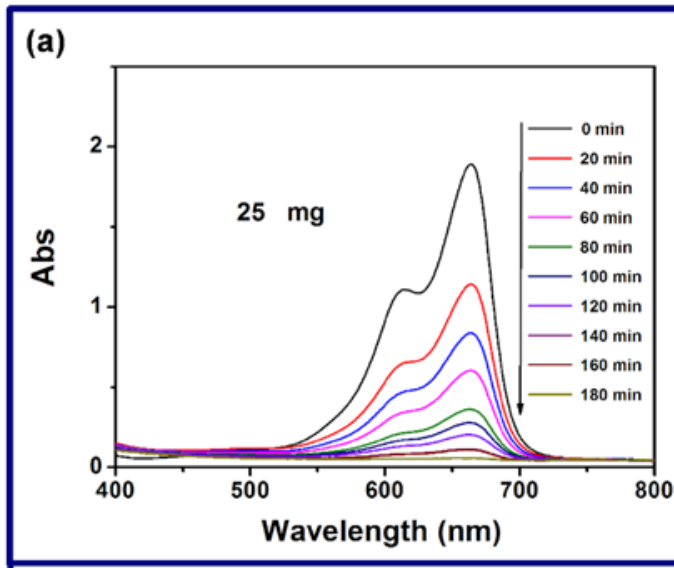

(b)
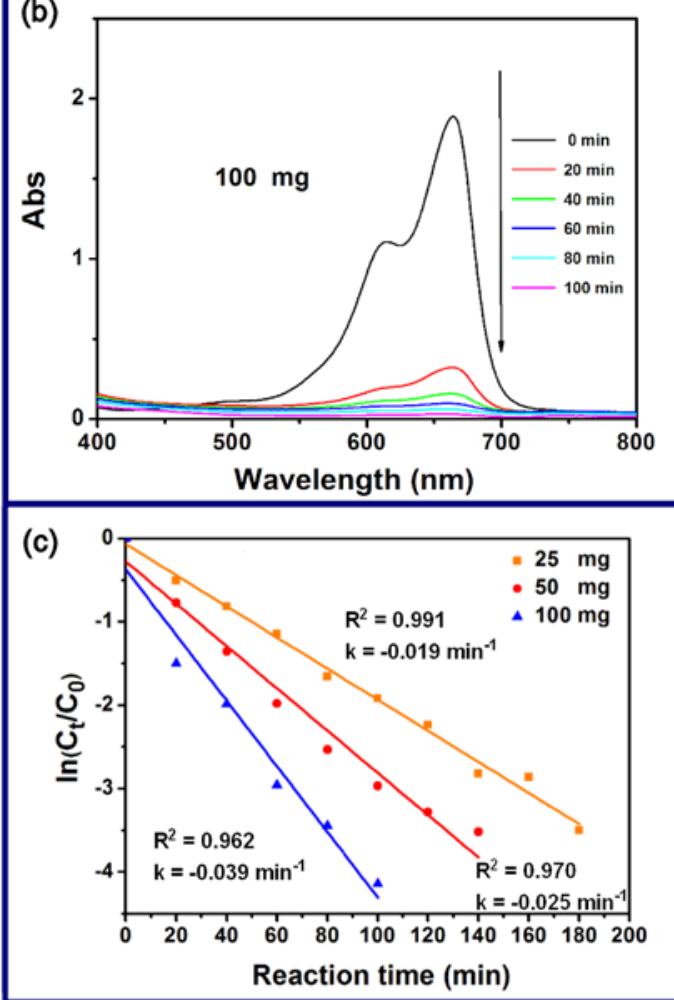

Figure 4. Effect of Tris-LDH-PW 12 dosage on the MB degradation. (a) $25 \mathrm{mg}$; (b) $100 \mathrm{mg}$ (c) reaction kinetic plots for the degradation of $\mathrm{MB}$ versus time. Experimental condition: $\mathrm{H}_{2} \mathrm{O}_{2}=500 \mu \mathrm{l} ; \mathrm{MB}=10 \mathrm{mg} / \mathrm{L}(50 \mathrm{ml}) ; \mathrm{T}=30{ }^{\circ} \mathrm{C}$.

\section{Effects of the initial $\mathrm{H}_{2} \mathrm{O}_{2}$ dosage}

As shown in Figure 5 , the initial dosage of $\mathrm{H}_{2} \mathrm{O}_{2}$ varied between $250 \mu \mathrm{l}$ and $1000 \mu \mathrm{l}$ for an initial dye concentration of 10 $\mathrm{mg} / \mathrm{L}$, and the effect of the $\mathrm{H}_{2} \mathrm{O}_{2}$ dosage on the dye degradation was measured. The results show that with the increase of $\mathrm{H}_{2} \mathrm{O}_{2}$ dosage from $250 \mu \mathrm{l}$ to $1000 \mu \mathrm{l}$, the dye degradation proceeds 
rapidly, and the experimental data can be fitted to a pseudo-firstorder equation. For the $\mathrm{H}_{2} \mathrm{O}_{2}$ dosage of $250 \mu \mathrm{l}$ and $500 \mu \mathrm{l}$, the experimental data can be fitted in two stages, 0 - 80 and 100 $160 \mathrm{~min}$ respectively, where the kinetic data are directly comparable (Figure 5). When the $\mathrm{H}_{2} \mathrm{O}_{2}$ dosage reaches the value of $1000 \mu \mathrm{l}$, the experimental data can be satisfactorily fitted giving a rate constant $\mathrm{k}$ of $0.042 \mathrm{~min}^{-1}$.
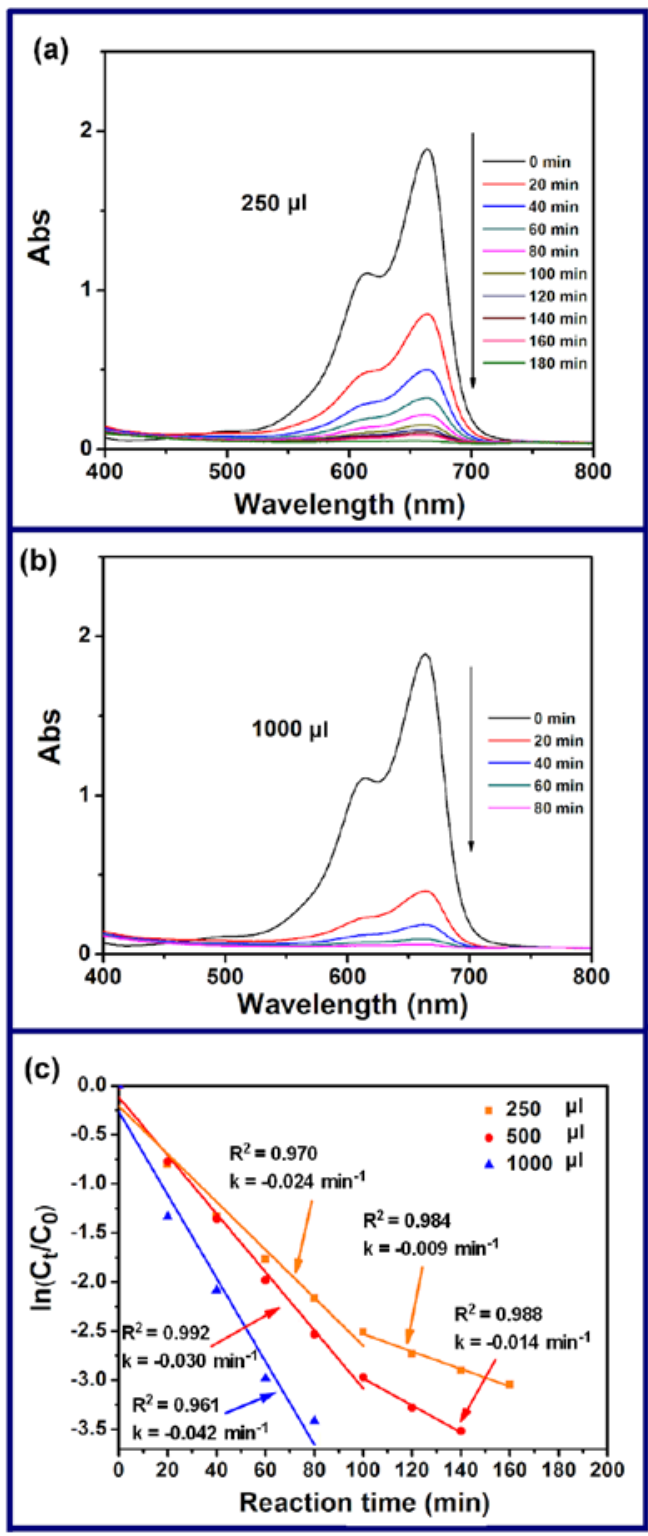

Figure 5. The effect of initial $\mathrm{H}_{2} \mathrm{O}_{2}$ dosage on the $M B$ degradation. (a) $\mathrm{H}_{2} \mathrm{O}_{2}=$ $250 \mu \mathrm{l}$; (b) $\mathrm{H}_{2} \mathrm{O}_{2}=1000 \mu \mathrm{l}$ (c) reaction kinetic plots for the degradation of $\mathrm{MB}$ versus time. Experiment condition: Tris-LDH-PW $1250 \mathrm{mg} ; \mathrm{MB}=10 \mathrm{mg} / \mathrm{L}(50$ $\mathrm{ml}) ; \mathrm{T}=30^{\circ} \mathrm{C}$.

\section{Effect of the initial dye concentration}

It is of practical important to investigate the effect of the initial pollutant concentration. Thus, we investigated the effect of initial dye concentration on the oxidation process, and the obtained results are shown in Figure S6. The initial concentration of $\mathrm{MB}$ used is 5,10 and $20 \mathrm{mg} / \mathrm{L}$, and the experimental results indicate the higher the initial dye concentration, the longer is the time required to degrade it completely and the lower is the degradation rate constant $k$. Similar results of the oxidation performance on the organic pollutes have been reported before in the literature. ${ }^{[36,37]}$

\section{Degradation of the mixed dyes solution}

Figure $6 a$ shows the degradation time of different dyes such as CV (Crystal Violet), MB (Methylene Blue) and RB (Rhodamine $B$ ) using Tris-LDH-PW $W_{12}$. When Tris-LDH-PW 12 is added to the aqueous solution of $C V, M B$ or $R B$ alone at room temperature, the dyes can be completely degraded within 5,140 or $320 \mathrm{~min}$, respectively.

In order to mimic the complex nature of industrial wastewater pollutants, three different dyes (CV, MB, and RB) have been mixed together in an aqueous solution at the same concentration (3.33 $\mathrm{mg} / \mathrm{L}$ each). The degradation efficiency of different dyes is presented in Figure $6 \mathrm{~b}$ as monitored by UV-vis absorption spectroscopy. The inset photographs highlight the degradation effects of the "contaminated" solution over time. The initially deep blue solution fades gradually, as a function of the degradation progression, to light blue, pink and finally colorless indicative of the complete dye removal. It is worth noting at this point that the LDH/PW 12 catalytic system exhibited selectivity against the utilized mixture of dyes which can be used for the selective removal of a specific substrate based on the reaction time. The degradation order is $C V>M B>R B$, see Figure $6 a$. The dyes can be degraded probably to less and/or non-toxic products such as $\mathrm{H}_{2} \mathrm{O}, \mathrm{CO}_{2}$ and mineral acids via a number of intermediate compounds. ${ }^{[38]}$

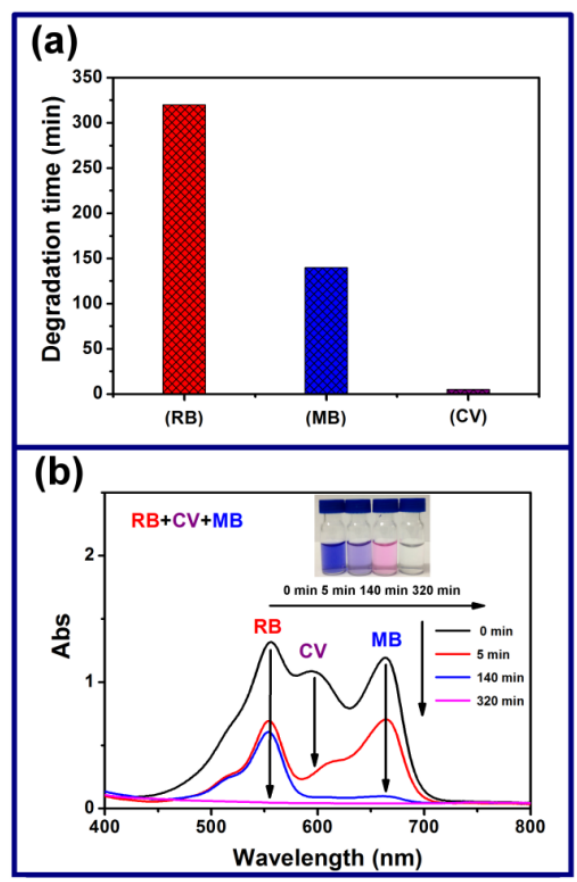

Figure 6. (a) Degradation time of different dyes. Experiment conditions: Tris LDH-PW $1250 \mathrm{mg} ; \mathrm{H}_{2} \mathrm{O}_{2}=500 \mu \mathrm{l} ;$ Dye $=10 \mathrm{mg} / \mathrm{L}(50 \mathrm{ml}) ; \mathrm{T}=30^{\circ} \mathrm{C}$. (b) The UV-Vis spectra of the mixed dyes degradation. Experiment condition: TrisLDH-PW $1250 \mathrm{mg} ; \mathrm{H}_{2} \mathrm{O}_{2}=500 \mu$; total dye $=10 \mathrm{mg} / \mathrm{L}(50 \mathrm{ml}$, Each dye $=3.33$ $\mathrm{mg} / \mathrm{L}) ; \mathrm{T}=30^{\circ} \mathrm{C}$ 


\section{Performance of different degradation systems and cooperative effects}

In an effort to evaluate the catalytic activity (if any) of the individual components we conducted a series of control experiments which demonstrate the existence of a cooperative effect between the composite material and $\mathrm{H}_{2} \mathrm{O}_{2}$ leading to amplified performance instead of a simple summative effect. In the presence of $\mathrm{H}_{2} \mathrm{O}_{2}$, Tris-LDH-P W exhibited $99 \% \mathrm{MB}$ degradation after $140 \mathrm{~min}$. In contrast, the application of Tris-LDH-PW 12 , Tris- $\mathrm{LDH}-\mathrm{CO}_{3} / \mathrm{H}_{2} \mathrm{O}_{2}$, Tris$\mathrm{LDH}-\mathrm{CO}_{3}, \mathrm{H}_{2} \mathrm{O}_{2}$ and Tris-LDH-P $\mathrm{W}_{12}+\mathrm{N}_{2}$ for dye degradation shows MB degradation percentage of $38,34,28,21$ and $10 \%$ after $140 \mathrm{~min}$, respectively (Figure 7 ). This result clearly demonstrates that neither the pristine Tris-LDH-CO (in the absence of $\mathrm{PW}_{12}$ ) nor the Tris-LDH-PW 12 (in the absence of $\mathrm{H}_{2} \mathrm{O}_{2}$ ) can perform as efficient oxidative dye degradation as observed in the case of Tris-LDH-PW 12 / $\mathrm{H}_{2} \mathrm{O}_{2}$ system. An important observation is that the $10 \%$ dye removal in the case of Tris-LDH-PW 12 (absence of $\mathrm{H}_{2} \mathrm{O}_{2}$ ) under $\mathrm{N}_{2}$ atmosphere (Figure 7) suggests that the substrate can access the catalytically active area of the Tris-LDH$\mathrm{PW}_{12}$ composite material.

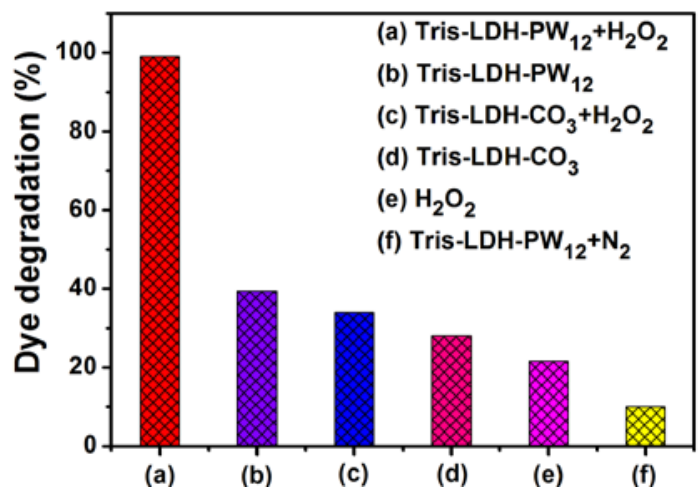

Figure 7. Comparison of the degradation efficiency using different catalytic systems in $140 \mathrm{~min}$. Experiment condition: $\mathrm{MB}=10 \mathrm{mg} / \mathrm{L}(50 \mathrm{ml}), \mathrm{T}=30{ }^{\circ} \mathrm{C}, \mathrm{t}$ $=140 \mathrm{~min}$; (a) Tris-LDH-PW $1250 \mathrm{mg}, \mathrm{H}_{2} \mathrm{O}_{2}=500 \mu \mathrm{l}$; (b) Tris-LDH-PW 1250 mg; (c) Tris-LDH-CO $50 \mathrm{mg}, \mathrm{H}_{2} \mathrm{O}_{2}=500 \mu \mathrm{l}$; (d) Tris-LDH-CO 50 mg; (e) $\mathrm{H}_{2} \mathrm{O}_{2}=500 \mu \mathrm{l}$; (f) Tris-LDH-PW $1250 \mathrm{mg}$ in $\mathrm{N}_{2}$ atmosphere.

Under the same experimental conditions, the use only of $\mathrm{PW}_{12}$ in the presence of $\mathrm{H}_{2} \mathrm{O}_{2}$ exhibits $99 \% \mathrm{MB}$ degradation in $140 \mathrm{~min}$ However, it is worth noting that the reason we do not use a homogeneous $\mathrm{PW} \mathrm{W}_{12} / \mathrm{H}_{2} \mathrm{O}_{2}$ system is because 1 ) the solubility of $\mathrm{PW}_{12}$ in water makes it unrecyclable and therefore can't be reused; 2) $\mathrm{PW}_{12}$ can cause secondary pollution. As such, it is not a good choice to apply the $\mathrm{PW}_{12} / \mathrm{H}_{2} \mathrm{O}_{2}$ system for dye degradation from sustainability point of view; 3 ) we cannot take advantage on the selective removal of toxic pollutants induced by the modular confined space of the composite material.

Since stability of the catalytic system is crucial for its practical application, it is essential to evaluate the recyclability of the catalyst. The Tris-LDH-PW 12 can be easily separated by centrifugation after completion of the degradation process, washed by deionized water, and dried before the next run. The results of the recycling test are shown in Figure $8 a$. The recycled
Tris-LDH-PW 12 can be used for at least ten times without obvious decrease of the catalytic activity (Figure 8a). Moreover, XRD patterns and FT-IR spectra of the recycled Tris-LDH-PW 12 (Figure S7) are in agreement with the one of the freshly prepared Tris-LDH-PW 12 , indicating the high stability of the composite catalyst during the dye degradation. Figure $8 \mathrm{~b}$ shows the XPS spectra of $W_{4 f}$ of the Tris-LDH-PW 12 after ten cycles, which can be deconvoluted into doublets. The doublet consists of $W 4 f_{7 / 2}$ at $35.5 \mathrm{eV}$ and $W 4 f_{5 / 2}$ at $37.5 \mathrm{eV}$, which can be assigned to the $\mathrm{W}-\mathrm{O}$ bond configuration and typically observed for the $W^{6+} \cdot{ }^{[26]}$ The results obtained by the XRD, FT-IR and XPS confirm the structural integrity of the Keggin structure in TrisLDH-PW 12 after ten cycles.
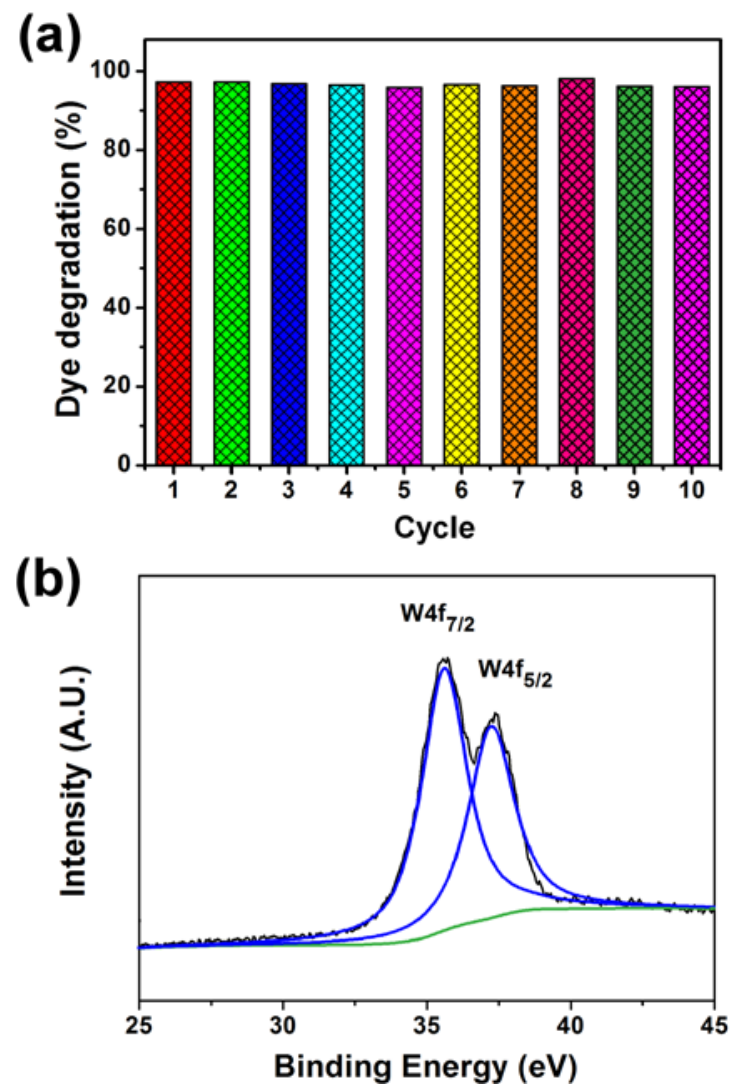

Figure 8. (a) Stability test of the Tris-LDH-PW 12 in $M B$ degradation Experiment condition: Tris-LDH-PW $1250 \mathrm{mg} ; \mathrm{H}_{2} \mathrm{O}_{2}=500 \mu \mathrm{l} ; \mathrm{MB}=10 \mathrm{mg} / \mathrm{L}$; $\mathrm{T}$ $=30{ }^{\circ} \mathrm{C}$; (b) XPS spectra for the $\mathrm{W} 4 \mathrm{f}$ core level spectrum of the Tris-LDH-PW recycled for ten times.

The degradation products were detected using ion chromatography. In comparison with the standard spectra of the typical degradation products ( $\mathrm{F}$ igure $\mathrm{S} 5$ ), the detected ions that can be clearly assigned are $\mathrm{NO}_{3}{ }^{-}, \mathrm{SO}_{4}{ }^{2-}, \mathrm{C}_{2} \mathrm{O}_{4}{ }^{2-}$ and other organic intermediates. ${ }^{[38]}$ The catalyst can be easily recovered by simple filtration.

\section{Conclusions}

To summarize, the exploitation and broad applicability of a facile method involving direct anion exchange of a series of POMs (Keggin, Dawson and Weakley) with Tris-modified LDHs under 
ambient conditions without the necessity of degassing $\mathrm{CO}_{2}$ has been reported, resulting in the formation of a new family of intercalated nanocomposite materials, namely Tris-LDH-PW 12 , Tris-LDH- $\mathrm{P}_{2} \mathrm{~W}_{18}$ and Tris-LDH-LaW 10 . It should be noted that it is unlikely to intercalate $\left[\mathrm{PW}_{12} \mathrm{O}_{40}\right]^{3-}$ into traditional $\mathrm{LDHs}$ by conventional ion exchange method due to the restriction of the negative charge of $\left[\mathrm{PW}_{12} \mathrm{O}_{40}\right]^{3-}$. Interestingly, XRD pattern of the as-synthesized Tris-LDH-POMs showed no impurity near (003), which is in striking contrast to the conventional POM intercalated LDH preparation methods reported so far.

Further investigation of Tris-LDH-POM composites for the degradation of three different dyes (RB, MB, and CV) in the presence of $\mathrm{H}_{2} \mathrm{O}_{2}$ exhibited enhanced catalytic activity for the Tris-LDH-PW 12 composite. Data obtained from BET analysis showed a correlation between the enhanced catalytic performance and the higher surface area of the LDH/PW 12 (15.9 $\mathrm{m}^{2} / \mathrm{g}$ ) comparing to the $\mathrm{LDH} / \mathrm{P}_{2} \mathrm{~W}_{18}\left(7.7 \mathrm{~m}^{2} / \mathrm{g}\right)$ and $\mathrm{LDH} / \mathrm{LaW}_{10}$ $\left(13.9 \mathrm{~m}^{2} / \mathrm{g}\right)$, respectively. Further, experimental investigation gave us the following important results: 1) the degradation process depends on the operation conditions such as reaction temperature, catalyst dosage, amount of $\mathrm{H}_{2} \mathrm{O}_{2}$, and the initial dye concentration; 2) The complete dye degradation can be achieved in $320 \mathrm{~min}$ for $\mathrm{RB}, 140 \mathrm{~min}$ for $\mathrm{MB}$, and $5 \mathrm{~min}$ for $\mathrm{CV}$, respectively. The degradation products have been identified as small non- or less toxic anions such as $\mathrm{SO}_{4}{ }^{2-}, \mathrm{NO}_{3}{ }^{-}, \mathrm{C}_{2} \mathrm{O}_{4}{ }^{2-}$ $\mathrm{CHO}^{2-}$ and $\mathrm{C}_{2} \mathrm{H}_{3} \mathrm{O}_{2}{ }^{2-} ; 3$ ) the designed interlayer accessible space greatly depends upon the POM's structure and consequently is totally modular and most importantly, promotes selectivity against specific substrates; 4) the Tris-LDH-PW 12 composite material can be readily recycled, washed, dried and reused at least ten times without obvious decrease of the catalytic efficiency.

Overall, we demonstrated the design of a fundamentally new family of modular catalytically active nanocomposite materials employing a facile intercalation methodology. Their modularity, catalytic efficiency and recyclability under energetically favorable conditions render them ideal candidates for industrial scale applications. The present work opens the door for further exploration and expansion of the present family of functional materials. The design of accessible interlayer space of specific size offers the opportunity for conducting chemical reactions in confined spaces whilst the general applicability of the synthetic methodology for the intercalation of functional anionic species demonstrates the vast potential for engineering multifunctional materials tailored for a wide range of applications.

\section{Experimental Section}

Materials and synthesis: All the used chemicals and solvents were purchased from Alfa Aesar and used directly without further purification. $\mathrm{Na}_{3}\left[\mathrm{PW}_{12} \mathrm{O}_{40}\right] \cdot 15 \mathrm{H}_{2} \mathrm{O}^{[39]}\left(\mathrm{Na}-\mathrm{PW} \mathrm{W}_{12}\right), \mathrm{K}_{6}\left[\mathrm{P}_{2} \mathrm{~W}_{18} \mathrm{O}_{62}\right] \cdot 14 \mathrm{H}_{2} \mathrm{O}^{[40]}\left(\mathrm{K}-\mathrm{P}_{2} \mathrm{~W}_{18}\right)$, $\mathrm{Na}_{9} \mathrm{LaW}_{10} \mathrm{O}_{36} \cdot 32 \mathrm{H}_{2} \mathrm{O}^{[41]}\left(\mathrm{Na}-\mathrm{LaW}_{10}\right)$ and the tripodal ligand-stabilized layered double hydroxide $\left(\mathrm{Tris}-\mathrm{LDH}-\mathrm{CO}_{3}\right)^{[21]}$ were synthesized according to the literature procedures, respectively. The POMs were intercalated into Tris- $\mathrm{LDH}-\mathrm{CO}_{3}$ by using anion-exchange method under $\mathrm{CO}_{2}$-existing conditions. Tris-LDH- $\mathrm{CO}_{3}(2 \mathrm{mg} / \mathrm{mL})$ was re-dispersed in the POM solution $(0.1 \mathrm{M})$ then stirred $2 \mathrm{~h}$ at room temperature. The precipitate was then filtered, washed with water and acetone, and dried in an oven to obtain the Tris-LDH-PW ${ }_{12}$, Tris-LDH- ${ }_{2} W_{18}$, or Tris-LDH-LaW 10 .

In a typical procedure, $\mathrm{K}_{6}\left[\mathrm{P}_{2} \mathrm{~W}_{18} \mathrm{O}_{62}\right]$ were intercalated into Tris-LDH$\mathrm{CO}_{3}$ by using anion-exchange method under $\mathrm{CO}_{2}$-existing conditions. Tris-LDH-CO $\mathrm{CO}_{3}(2 \mathrm{mg} / \mathrm{mL})$ was re-dispersed in the $\mathrm{K}_{6}\left[\mathrm{P}_{2} \mathrm{~W}_{18} \mathrm{O}_{62}\right]$ solution
$(0.1 \mathrm{M})$ then stirred $2 \mathrm{~h}$ at room temperature. The precipitate was then filtered, washed with water and acetone, and dried in an oven to obtain the Tris-LDH- ${ }_{2} W_{18}$. Tris-LDH-PW 12 and Tris-LDH-LaW 10 were obtained using similar procedure as above.

Inductively coupled plasma emission spectroscopy (ICP-ES) measurement indicates that the $\mathrm{W}^{6+}$ content of $232 \mu \mathrm{mol} / \mathrm{g}$ in Tris-LDH$\mathrm{P}_{2} \mathrm{~W}_{18}, 270 \mu \mathrm{mol} / \mathrm{g}$ for Tris-LDH-PW 12 , and $207 \mu \mathrm{mol} / \mathrm{g}$ for Tris-LDHLaW $_{10}$; FT-IR $\left(K B r, c^{-1}\right.$, Tris-LDH-P $\left.{ }_{2} W_{18}\right): 1 / 2=1092\left(P-O_{a}\right), 959\left(\mathrm{~W}-\mathrm{O}_{\mathrm{d}}\right)$, $907\left(\mathrm{~W}-\mathrm{O}_{\mathrm{b}}-\mathrm{W}\right)$. For Tris-LDH-PW 12 : $1 / 2=1072\left(\mathrm{P}-\mathrm{O}_{\mathrm{a}}\right), 955\left(\mathrm{~W}-\mathrm{O}_{\mathrm{d}}\right), 894$ $\left(\mathrm{W}-\mathrm{O}_{\mathrm{b}}-\mathrm{W}\right), 811\left(\mathrm{~W}-\mathrm{O}_{\mathrm{c}}-\mathrm{W}\right)$; F or Tris-LDH-LaW 10 : $1 / 2=940\left(\mathrm{~W}-\mathrm{O}_{\mathrm{d}}\right), 848(\mathrm{~W}-$ $\left.\mathrm{O}_{\mathrm{b}}-\mathrm{W}\right), 701\left(\mathrm{~W}-\mathrm{O}_{\mathrm{c}}-\mathrm{W}\right)$ ]; ${ }^{31} \mathrm{P}$ CP/MAS NMR $(121.0 \mathrm{MHz}, \mathrm{ppm})^{\prime}=-6.5$ $\left[\right.$ Tris-LDH-PW $12{ }^{\prime}=-4$ ].

Catalyst characterizations: Powder X-ray diffraction (XRD) patterns were recorded on a Rigaku XRD-6000 diffractometer under the following conditions: $40 \mathrm{kV}, 30 \mathrm{~mA}, \mathrm{Cu} \mathrm{K} \pm$ radiation (» $=0.154 \mathrm{~nm}$ ). FT-IR spectra were recorded on a Bruker Vector 22 infrared spectrometer by using $\mathrm{KBr}$ pellets. The solid state NMR experiments were carried out at $75.6 \mathrm{MHz}$ for ${ }^{13} \mathrm{C}$ and $121.0 \mathrm{MHz}$ for ${ }^{31} \mathrm{P}$ on a Bruker Avance $300 \mathrm{M}$ solid-state spectrometer equipped with a commercial $5 \mathrm{~mm}$ MAS NMR probe. The $\mathrm{N}_{2}$ adsorption-desorption isotherms were measured using Quantachrome Autosorb-1 system at liquid nitrogen temperature. Scanning electron microscopy (SEM) images and energy dispersive X-ray (EDX) analytical data were obtained using a Zeiss Supra 55 SEM equipped with an EDX detector. Transmission electron microscopy (TEM) micrographs were recorded using a Hitachi $\mathrm{H}-800$ instrument. HRTEM images were conducted on a JEOL JEM-2010 electron microscope operating at 200 $\mathrm{kV}$. Thermogravimetric and differential thermal analyses (TG-DTA) were performed on a TGA/DSC $1 / 1100 \mathrm{SF}$ from Mettler Toledo in flowing $\mathrm{N}_{2}$ with a heating rate of $10{ }^{\circ} \mathrm{C} \cdot \mathrm{min}^{-1}$ from $25{ }^{\circ} \mathrm{C}$ to $1000^{\circ} \mathrm{C}$. X-ray photoelectron spectroscopy (XPS) measurements were performed with monochromatized $\mathrm{Al} \mathrm{K} \pm$ exciting X-radiation ( $\mathrm{PHI}$ Quantera $\mathrm{SXM}$ ). Inductively coupled plasma emission spectroscopy (ICP-ES, Shimadzu ICPS-7500) was used to measure the concentration of $W$ in the catalysts.

Catalytic performance testing: The catalytic performance of the prepared Tris-LDH-PW 12 catalysts was determined by measuring the degradation of high concentration dyes in the presence of $\mathrm{H}_{2} \mathrm{O}_{2}$. Three typical dyes, including methylene blue ( $M B, \mathrm{C}_{16} \mathrm{H}_{18} \mathrm{CIN}_{3} \mathrm{~S}$ ), rhodamine $\mathrm{B}$ $\left(\mathrm{RB}, \mathrm{C}_{28} \mathrm{H}_{31} \mathrm{CIN}_{2} \mathrm{O}_{3}\right)$ and crystal violet $\left(\mathrm{CV}, \mathrm{C}_{25} \mathrm{H}_{30} \mathrm{CIN} \mathrm{N}_{3}\right)$ were selected as the degradation target molecules. In a typical process, $50 \mathrm{mg}$ Tris-LDH$\mathrm{PW}_{12}$ catalysts were added into $50 \mathrm{~mL} \mathrm{MB}$ solution $(10 \mathrm{mg} / \mathrm{L})$ under stirring, followed by addition of $500 \mu \mathrm{H} \mathrm{H}_{2} \mathrm{O}_{2}$ solution (30 wt.\%). The reaction temperature is maintained at $30{ }^{\circ} \mathrm{C} \pm 0.5{ }^{\circ} \mathrm{C}$ in a water-bath. During the catalytic process, reaction solution is sampled at different time intervals and its absorption intensity was determined using a UV-visible spectrophotometer (TU-1901). The dye concentration was measured at the maximum absorption wavelength of the dye. The maximum absorption wavelengths are 664,554 , and $584 \mathrm{~nm}$ for MB, RB and CV respectively.

\section{Acknowledgements}

This research was supported by National Basic Research Program of China (2014CB932104), the National Science Foundation of China (21222104), the Fundamental Research Funds for the Central Universities (RC1302, YS1406) and Beijing Engineering Center for Hierarchical Catalysts. H.N.M acknowledges the financial support from Univergisity of Glasgow, Royal Society of Edinburhg and Marie Curie actions.

Keywords: polyoxometalate $\bullet$ layered double hydroxides $\bullet$ dyes - catalysis $\cdot$ degradation

[1] W. G. Kuo, Water Res. 1992, 26, 881-886. 
[2] B. H. Hameed, A. A. Ahmad, N. Aziz, Chem. Eng. J . 2007, 133, 195203.

[3] J.J ia, J. Yang, J . Liao, W. Wang, Z. Wang, Water Res. 1999, 33, 881 884.

[4] J. H. Mo, Y. H. Lee, J. Kim, J. Y. J eong, J . J egal, Dyes Pigments 2008, $76,429-434$

[5] a) C. Chen, W. Ma, J. Zhao, Chem. Soc. Rev. 2010, 39, 4206-4219; b) J. Tucher, S. Schlicht, F. Kollhoff and C. Streb, Dalton Trans. 2014, 43, 17029-17033; c) A. Seliverstov and C. Streb, Chem. Eur. J. 2014, 20 9733-9738.

[6] a) W. Zhao, W. Ma, C. Chen, J. Zhao, Z. Shuai, J. Am. Chem. Soc. 2004, 126, 4782-4783; b) A. Seliverstov and C. Streb, Chem. Commun. 2014, 50, 1827-1829.

[7] C. K. Duesterberg, S. E. Mylon, T. D. Waite, Environ. Sci. Technol. 2008, 42, 8522-8527.

[8] N. Azbar, T. Yonar, K. Kestioglu, Chemosphere 2004, 55, 35-43.

[9] E. Kusvuran, O. Gulnaz, S. Irmak, O. M. Atanur, H. Ibrahim Yavuz, O. Erbatur, J. Hazard. Mater. 2004, 109, 85-93.

[10] A. H. Gemeay, I. A. Mansour, R. G. El-Sharkawy, A. B. Zaki, J. Mol. Catal. A: Chem. 2003, 193, 109-120.

[11] M. Cheng, W. Ma, J. Li, Y. Huang, J. Zhao, Y. X. Wen, Y. Xu, Environ. Sci. Technol. 2004, 38, 1569-1575.

[12] Q. Wang, D. O'Hare , Chem. Rev. 2012, 112, 4124-4155.

[13] G. R. Williams ,D. O'Hare ,J. Mater. Chem. 2006, 16, 3065-3074.

[14] D. Yan , J. Lu, M. Wei ,S. Qin , L. Chen, S. Zhang, D. G. Evans , X. Duan, Adv. Funct. Mater. 2011, 21, 2497-2505.

[15] A. Illaik, C. Taviot-Guého , J. Lavis, S. Commereuc ,V. Verney , F. Leroux , Chem. Mater. 2008, 20, 4854-4860.

[16] M. Q. Zhao, Q. Zhang, J. Q. Huang, F. W ei, Adv. Funct. Mater. 2012, 22 675-695.

[17] Y. F. Zhao, P. Y. Chen, B. S. Zhang, D. S. Su, S. T. Zhang, L. Tian, J. Lu, Z. X. Li, X. Z. Cao, B. Y. Wang, M. Wei, D. G. Evans, X. Duan, Chem. Eur. J . 2012, 18, 11949-11958.

[18] a) E. D. Dimotakis, T. J. Pinnavaia, Inorg. Chem. 1990, 29, 2393-2394; b) T. Kwon, T. J. Pinnavaia, J. Mol. Catal. 1992, 74, 23-33.

[19] a) S. Zhao, J. Xu, M. Wei, Y.-F. Song, Green Chem. 2011, 13, 384-389; b) Y. Chen, D. Yan, Y.-F. Song, Dalton Trans., 2014, 43, 14570-14576.

[20] J. Xu, S. Zhao, Z. Han, X. Wang, Y. F. Song, Chem. Eur. J. 2011, 17, 10365-10371.
[21] Z. Han, Y. Guo, R. Tsunashima, Y. F. Song, E ur. J . Inorg. Chem, 2013, 1475-1480.

[22] S. Omwoma, W. Chen, Y. F. Song, Coord. Chem. Rev. 2014, 258-259, 58-71.

[23] Y. Kuroda, Y. Miyamoto, M. Hibino, K. Yamaguchi, N. Mizuno, Chem. Mater. 2013, 25, 2291-2296.

[24] Y. Guo, C. Hu, S. Jiang, C. Guo, Y. Yang, E. Wang, Appl. Catal. B: Environ. 2002, 36, 9-17.

[25] T. F. Otero, S. A. Cheng, D. Alonso, F. Huerta, J Phys Chem B. 2000 104, 10528-10533.

[26] L. Salvati, L. E. Makovsky, J . M. Stencel, F. R. Brown, D. M. Hercules, J. Phys. Chem. 1981, 85, 3700-3707.

[27] a) M. V. Luzgin, A. G. Stepanov, J. Phys. Chem. C 2014, 118, 21042-21048; b) Y. Kanda, K. Y. Lee, S. Nakata, S. Asaoka, M. Misono, Chem. Lett. 1988, 139-142.

[28] Y. Kuroda, Y. Miyamoto, M. Hibino, K. Yamaguchi, N. Mizuno, Chem. Mater. 2013, 25, 2291-2296.

[29] B. J. Aronson, C. F. Blanford, A. Stein, Chem. Mater. 1997, 9, $2842-$ 2851.

[30] J.H. Ramirez, F. J. Maldonado-Hódar, A. F. Pérez-Cadenas, C. Moreno-Castilla, C. A. Costa, L. M. Madeira, Appl. Catal. B: Environ. 2007, 75, 312-323.

[31] M. L. Rache, A. R. García, H. R. Zea, A. M. T. Silva, L. M. Madeira, J. H. Ramírez, Appl. Catal. B: Environ. 2014, 146, 192-200.

[32] L. Liu, J. Zhang, Y. Tan, Y. J iang, M. Hu, S. Li, Q. Zhai, Chem. Eng. J. 2014, 244, 9-18.

[33] Y. Leng, W. Guo, X. Shi, Y. Li, A. Wang, F. Hao, L. Xing, Chem. Eng. J 2014, 240, 338-343.

[34] M. Amini, B. Pourbadiei, T. P. A. Ruberu, L. K. W oo, New J . Chem. 2014, 38, 1250-1255.

[35] S. Liu, W. Peng, H. Sun, S. Wang, Nanoscale 2014, 6, 766-771.

[36] J. Guo, M. Al-Dahhan, Ind. Eng. Chem. Res. 2003, 42, 2450-2460.

[37] A. Pintar, J . Levec, J. Catal. 1992, 135, 345-357.

[38] Q. Wang, S. Tian, P. Ning, Ind. Eng. Chem. Res. 2013, 53, 643-649.

[39] N. Chen, R. T. Yang, J. Catal. 1995, 157, 76-86.

[40] C. R. Graham, R. G. Finke, Inorg. Chem. 2008, 47, 3679-3686.

[41] R. D. Peacock, T. J. R. Weakley, J. Chem. Soc. A 1971, 1836-1839. 
